ИЗВЕСТИЯ АКАДЕМИИ НАУК ЭСТОНСКОП ССР. ТОМ 25 ХИМИЯ * ГЕОЛОГИЯ. 1976, № 3

\title{
НОВЫЕ ДАННЫЕ О ФЛОРЕ И РАСТИТЕЛЬНОСТИ РАЗРЕЗА КАРУКЮЛА В ЭСТОНИИ
}

Межморенные отложения у д. Карукюла (Юго-Западная Әстония), открытые и обследованные в 1941 г. К. Орвику, первоначально были отнесены ко второму климатическому оптимуму эмского (микулинского) межледниковья (Орвику, 1956), а позднее стали датироваться брёрупским интерстадиалом (Орвику, Пиррус, 1965). В последнее десятилетие, в связи с резко возросшим интересом к проблемам истории четвертичного периода, неоднократно предпринимались попытки исследования карукюлаского разреза геологическими, палеоботаническими, физико-химическими и другими методами.

K настоящему времени по разрезу Карукюла накопилась обширная литература, свидетельствующая об отсутствии единой точки зрения на возраст органогенных отложений данного разреза. Не вдаваясь в детали существующих по этому вопросу разногласий, следует отметить, что подавляющее большинство исследователей придерживается мнения о молодом, позднеплейстоценовом возрасте межморенных слоев и связывает их образование либо со средневалдайским потеплением (Пуннинг и др., 1967; и др.), которому придается ранг межледниковья или интерстадиала, либо с ранневалдайским интерстадиалом, сопоставляемым с брёрупским в Западной Европе. Иного взгляда придерживаются Л. Н. Вознячук (1966) и И. Я. Даниланс (1966), высказавшие предположение о лихвинском возрасте карукюлаского разреза. К такому же выводу склоняется и Э. Лийвранд (1972). В настоящей статье авторами приведены новые данные, в основном палеокарпологические, подтвердившие правомерность последнего предположения.

Первые сведения о семенной флоре карукюласких органогенных отложений получены Т. Д. Колесниковой (Каяк и др., 1970; Лийвранд, 1972), которой удалось обнаружить здесь остатки лишь немногих растений (Salvinia natans (L.) All., Picea abies (L.) Karst., Carex rostrata Stokes, C. elongata L., Potamogeton sp., Alnus glutinosa (L.) Gaertn.). Судить o возрасте флороносных отложений на основании этих, очень фрагментарных данных практически невозможно, поэтому весной 1975 г. авторами было предпринято повторное палеоботаническое изучение семян, а также пыльцы и спор карукюлаского разреза. Для отбора образцов на оба анализа был заложен шурф, вскрывший следующие слои: 
1. Почвенно-растительный слой . . . . . . . . . $0,00-0,30$

2. Красно-бурая морена . . . . . . . . . . . . $0,30-1,00$

3. Песок разнозернистый, желтоватый . . . . . . 1,00-1,27

4. Торф лесной, с большим количеством обломков древесины и мелкого растительного детрита . . . . 1,27-1,70

5. Торф тростниково-лесной . . . . . . . . . . 1,70-1,80

6. Торф тростниковый, листоватый . . . . . . . . . $1,80-2,25$

7. Сапропелит темно-серый до черного . . . . . . 2 2,25-2,60

8. Алеврит глинистый, серый ․ . . . . . . . 2, 2,60-2,85

9. Песок разнозернистый, желтоватый, с зернами гравия .

$2,85-3,20$

Сапропелит шурфа Д, содержащий наиболее разнообразную ископаемую флору, постепенно уменьшается в мощности вплоть до полного выклинивания. Поэтому в целях получения более полного разреза для палинологического анализа использовались образцы сапропелита из соседнего, ранее заложенного шурфа А, где его мощность наибольшая (рисунок).

Бурением было установлено, что озерно-болотные отложения покоятся на мощной толще (до 35 м) флювиогляциальных образований, залегающих непосредственно на девонских породах. Выдержанный слой среднеплейстоценовой или нижневалдайской серой морены, который по прежним представлениям (Каяк и др., 1970) подстилал линзу органогенных образований, обнаружен не был, но фрагменты серой морены мощностью $0,05-0,5 м$ встречаются во флювиогляциальных отложениях. Примечательно, что там же обнаружены куски сапропелита и торфа. Такие условия залегания озерно-болотных отложений не только не могут расцениваться как доказательство их позднеплейстоценового возраста, но и наводят на мысль о возможной отторженцевой природе карукюлаской органогенной толщи. Столь же альтернативны выводы о возрасте рассматриваемого разреза, опирающиеся на радиоуглеродные датировки, среди которых есть как конечные, так и запредельные.

Таблища 1

Семенная флора разреза Карукюла (шурф Д)

\begin{tabular}{|c|c|c|c|c|c|}
\hline \multirow[b]{2}{*}{ P астение } & \multicolumn{5}{|c|}{ Глубина отбора образцов, м } \\
\hline & 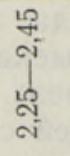 & 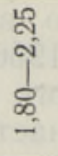 & $\frac{\infty}{-1}$ & \begin{tabular}{l} 
웅 \\
I \\
0 \\
\hdashline
\end{tabular} & 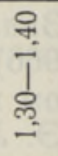 \\
\hline 1 & 2 & 3 & 4 & 5 & 6 \\
\hline $\begin{array}{l}\text { Bryales gen. } \\
\text { Characeae gen. gen. } \\
\text { Salvinia natans (L.) All. } \\
\text { Selaginella selaginoides (L.) Lk. } \\
\text { Isoetes cf. lacustris L. } \\
\text { Picea cf. abies (L.) Karst. } \\
\text { Pinus sp. } \\
\text { Larix sp. } \\
\text { Typha sp. } \\
\text { Sparganium e gr. minimum Fries } \\
\text { Potamogeton natans L. } \\
\text { P. alpinus Balb. }\end{array}$ & $\begin{array}{r}+ \\
3 \\
\mathrm{OM} \\
8 \\
-5 \\
5 \\
+ \\
\mathrm{MH} \\
\mathrm{OM} \\
1 \\
5 \\
1\end{array}$ & $\begin{array}{r}\frac{+}{\mathrm{MH}} \\
\frac{-}{-} \\
43 \\
1 \\
1 \\
\mathrm{MH} \\
1 \\
-\end{array}$ & $\begin{array}{l} \pm \\
\overline{-} \\
\overline{2} \\
\overline{27} \\
\overline{12} \\
\overline{-}\end{array}$ & $\begin{array}{l} \pm \\
\overline{-} \\
\overline{-} \\
\overline{\mathrm{MH}} \\
\overline{-} \\
10 \\
\frac{1}{-}\end{array}$ & $\begin{array}{r}\overline{\mathrm{MH}} \\
2 \\
-5 \\
5 \\
\mathrm{MH} \\
- \\
\mathrm{MH} \\
4 \\
-\end{array}$ \\
\hline
\end{tabular}




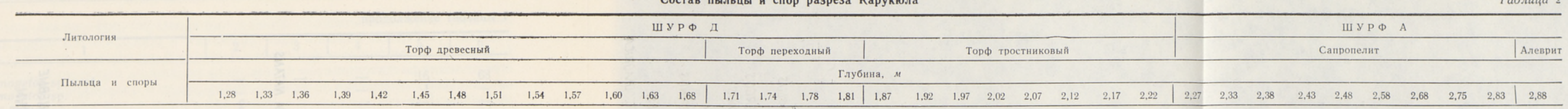

Общее количество зерен $\begin{array}{lllllllllllllllllllllllllllllllllll}795 & 827 & 690 & 702 & 613 & 488 & 456 & 350 & 319 & 352 & 485 & 324 & 398 & 370 & 360 & 546 & 458 & 515 & 1215 & 555 & 684 & 778 & 1267 & 1004 & 1183 & 659 & 493 & 393 & 425 & 676 & 449 & 470 & 547 & 460 & 521 \\ 486 & 448 & 392 & 426 & 360 & 290 & 258 & 213 & 207 & 206 & 266 & 217 & 273 & 289 & 302 & 280 & 278 & 222 & 330 & 180 & 221 & 195 & 260 & 228 & 337 & 579 & 432 & 340 & 397 & 605 & 390 & 347 & 418 & 321 & 267 \\ 208 & 218 & 179 & 178 & 153 & 131 & 91 & 83 & 25 & 38 & 13 & 27 & 65 & 25 & 50 & 121 & 76 & 62 & 67 & 22 & 52 & 52 & 108 & 78 & 90 & 11 & 12 & 13 & 2 & 27 & 15 & 8 & 14 & 50 & 73 \\ 101 & 161 & 119 & 98 & 100 & 67 & 107 & 54 & 87 & 108 & 161 & 80 & 60 & 56 & 28 & 145 & 104 & 231 & 818 & 353 & 441 & 531 & 899 & 698 & 756 & 69 & 49 & 40 & 26 & 44 & 44 & 115 & 115 & 89 & 181\end{array}$ Пыльца древесных поро

Спор

Larix
Abies

Picea P. sec. Omorica

Pinus

Betula Bec. Albae

B. sec. Albae
B. humilis
B. nana

Quercus

Ulmus

T. platyphyllos

cf. tomento

Carpinus

Myrice

Alnus
A. glutinosa
A. incana

Corylus

Ligustrum

Gramineae

Cyperacea
Ericales

Chenopodiaceae

Eurotia ceratoides
Salicornia herbacea

Chenopodium botrys

Helianthemum
Artemisia

Compositac

Rosaceae

Caryophyllacea

Umbelliferae
Violaceae

Trapa natat

Myriophyllum spicatum

M. verticillatu
Typha sp.

Sparganium
Heопределеннь

Bryales
Polypodiaceae

Sphagnum

Equisetum

L., annotinum

Selaginella selaginoides

O. cinnamonea

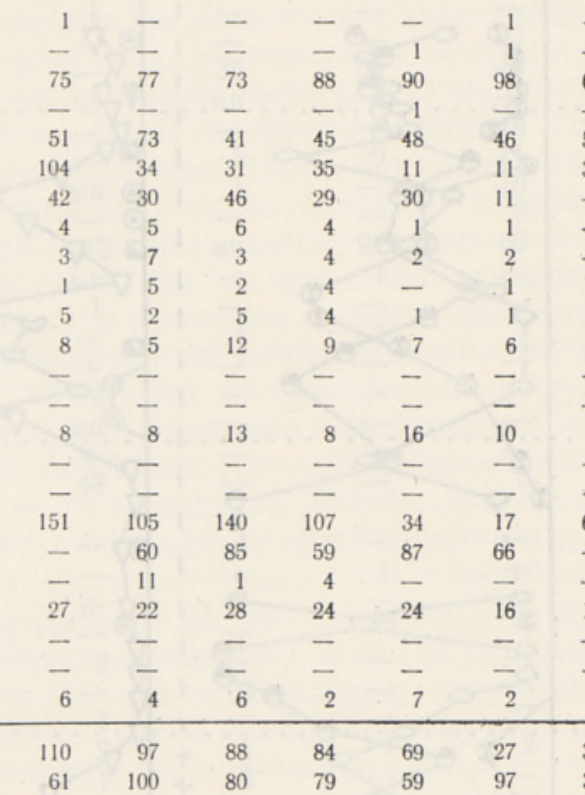

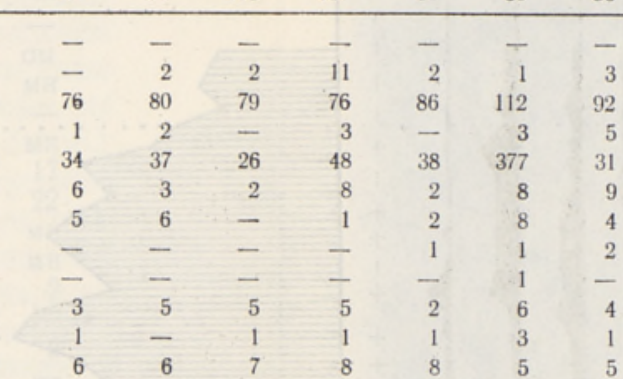




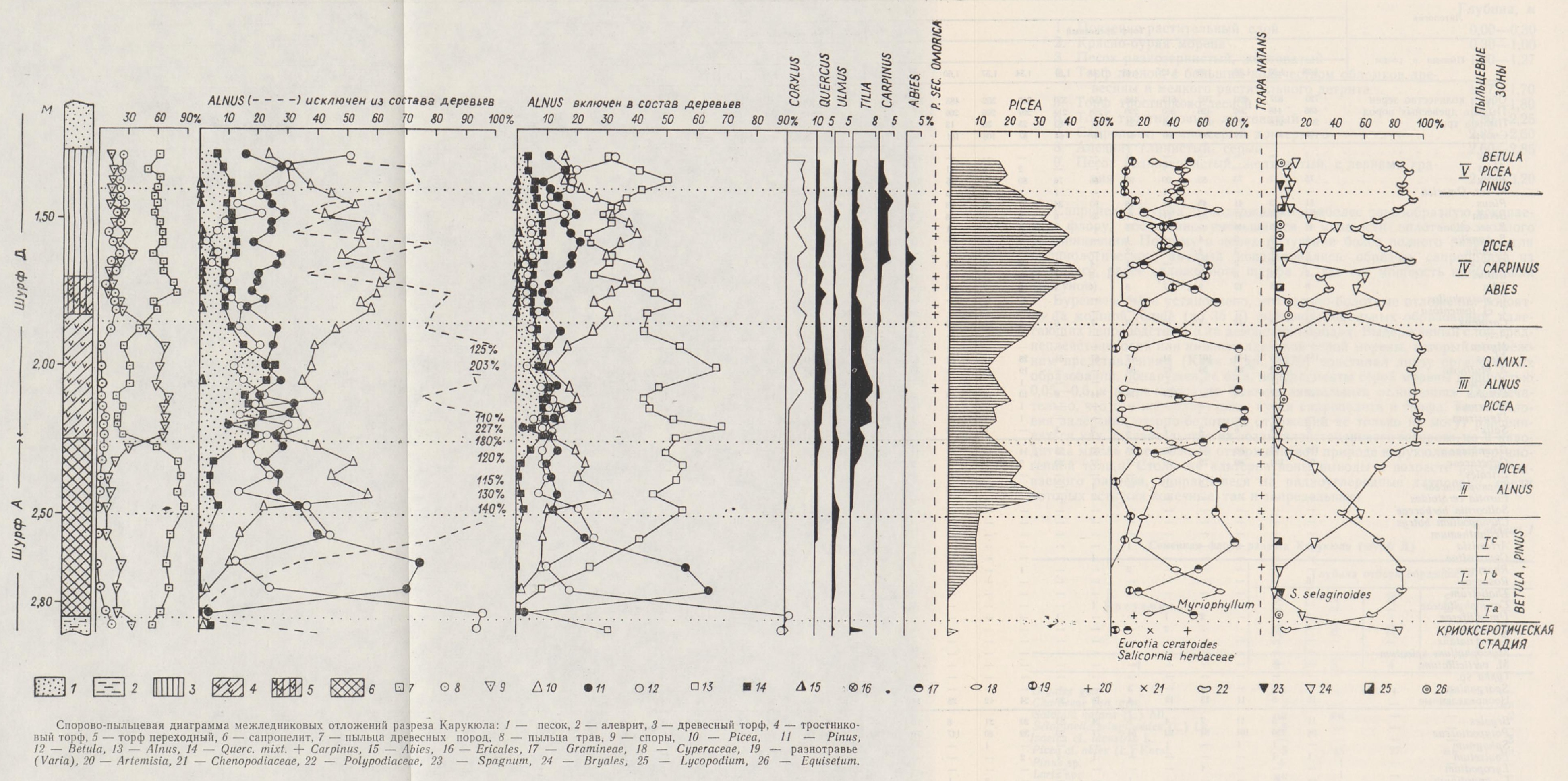


продолжение таблицы 1

\begin{tabular}{ll|l|l|l|l|l}
\hline 1 & 2 & 3 & 4 & 5 & 6 \\
\hline
\end{tabular}

Potamogeton sp. exot.

Potamogeton sp.

Najas marina

Alisma plantago-aquatica L.

Sagittaria sagittifolia L.

Stratiotes sp.

Dulichium cf. arundinaceum (L.) Britt.

Scirpus lacustris L.

S. e gr. sylvaticus L.

Carex inflata Huds.

C. pseudocyperus L.

C. paucifloroides Wieliczk.

C. s/gen. Vignea

Calla palustris $\mathrm{L}$.

Betula alba L.

$B$. humilis Schrank.

Alnus glutinosa (L.) Gaertn.

Urtica dioica L.

Rumex maritimus L.

Stellaria palustris Ehrh.

Brasenia sp.

Nymphaea sp. exot.

Nuphar cf. lutea (L.) Smith

Ceratophyllum sp.

Ranunculus ci. sceleratoides Nikit. et

Dorof.

$R$. e gr. sceleratus L.

$R$. cf. flammula L.

Ranunculus sp. 1

Ranunculus sp. 2

Rorippa islandica (Oeder) Borbas

Aldrovanda cf. dokturovskyi Dorof.

Comarum palustre L.

Rubus idaeus L.

Fragaria vesca L.

Filipendula cí. ulmaria (L.) Maxim.

Frangula alnus Mill.

Hypericum sp.

Myriophyllum verticillatum $\mathrm{L}$.

Hippuris vulgaris L.

Swida sp.

Naumburgia thyrsiflora (L.) Rchb.

Menyanthes trifoliata $\mathrm{L}$.

Lycopus cf. europaeus L.

Mentha sp.

Scrophulariaceae gen.

Solanum sp.

Eupatorium cannabinum L.

Compositae gen.

\begin{tabular}{|c|c|c|c|c|}
\hline - & - & - & 16 & 68 \\
\hline & - & - & 1 & - \\
\hline 2 & - & - & - & 一 \\
\hline 25 & - & 1 & 7 & 24 \\
\hline 1 & - & - & - & - \\
\hline+ & - & - & $\bar{T}_{1}$ & $\overline{4}$ \\
\hline & - & $\overline{-}$ & 1 & 4 \\
\hline 1 & - & - & - & - \\
\hline & - & - & 23 & $\mathrm{OM}$ \\
\hline & 36 & 58 & MH & MH \\
\hline & MH & - & - & - \\
\hline & $\overline{5}$ & $\overline{0}$ & $\mathrm{MH}$ & MH \\
\hline & 1 & - & 10 & 22 \\
\hline & - & - & 5 & $\mathrm{MH}$ \\
\hline 2 & MH & 91 & 69 & $\mathrm{MH}$ \\
\hline H & - & 1 & - & 2 \\
\hline & -1 & 7 & 7 & $\overline{0}$ \\
\hline & - & 1 & 1 & 2 \\
\hline 4 & - & - & - & - \\
\hline MH & - & - & - & - \\
\hline & - & - & - & \\
\hline 48 & - & - & 5 & 19 \\
\hline & 1 & - & - & - \\
\hline & - & 1 & - & - \\
\hline & - & - & - & - \\
\hline & - & - & 1 & 1 \\
\hline & $\overline{2}$ & $\overline{-}$ & $\bar{z}$ & - \\
\hline 1 & - & - & 27 & 19 \\
\hline 2 & 1 & 1 & 2 & 6 \\
\hline & 1 & - & - & - \\
\hline- & 1 & 26 & OM & OM \\
\hline- & 1 & - & 5 & 10 \\
\hline 2 & E & $\bar{Z}$ & - & - \\
\hline & - & - & - & - \\
\hline+ & - & - & - & - \\
\hline & - & - & 1 & - \\
\hline $1:$ & $\overline{7}$ & 7 & $\overline{0}$ & 101 \\
\hline 12 & 2 & - & - & 21 \\
\hline & - & - & 1 & - \\
\hline & - & - & - & 2 \\
\hline & - & & - & - \\
\hline & - & - & - & 1 \\
\hline
\end{tabular}

Условные обозначения: ом - более 200 остатков, мн - более 100 остатков, + - растение представлено фрагментами плодов, семян.

По образцам сапропелита, тростникового и лесного торфов получена богатая ископаемая флора (табл. 1), которая позволяет вполне определенно решить вопрос о возрасте вмещающих отложений. Флора происходит из сильно спрессованных торфов и минерализованного сапропелита, что наложило соответствующий отпечаток как на состав, так и на внешний вид растительных остатков. Несмотря на то что многие растения представлены деформированными, трудно распознаваемыми остатками, а то и вовсе фрагментами плодов и семян, допускающими лишь родовые опре- 
деления, сохранилось немало совершенно целых макрофоссилий, пригодных для уверенной видовой идентификации и обоснованной корреляции с другими ископаемыми флорами. Известную сложность представляло и выделение растительных остатк в из включающих отложений, потребовавшее более трудоемкой, нежели традиционная палеокарпологическая, методики. Все это привело к неизбежной утрате части макрофоссилий с хрупкими, легко разрушающимися оболочками и, как следствие этого, к недостаточной выявленности флоры. Тем не менее полученный растительный комплекс отличает целостность, бесспорная монохронность, достаточное богатство и разнообразие систематического состава. Одной из основных и наиболее очевидных особенностей рассматриваемой флоры является ее ярко выраженный межледниковый тип. Представительная группа травянистых термофильных растений (Salvinia, Najas, Stratiotes, Dulichium, Brasenia, Nymphaea, Nupher, Ceratophyllum, Aldrovanda и др.), образующая характерный только для настоящих межледниковых флор «бразениевый» комплекс, исключает интерстадиальную природу теплого интервала, в течение которого происходило накопление толщи органогенных осадков. Об этом же свидетельствует высокое систематическое разнообразие флоры в целом, ее отчетливо выраженный лесной характер, практически полное отсутствие холодостойких видов бореально-арктического комплекса. Во флоре, правда, установлены Selaginella selaginoides и Betula humilis - обычные компоненты лесных и лесотундровых интерстадиальных флор, однако первый вид соседствует с Brasenia, Salvinia, Nymphaea, второй же приурочен к верхам флороносной толщи и может отражать некоторое ухудшение климата послеоптимальных фаз межледниковья.

Другой характерной чертой рассматриваемой флоры является ее неоспоримая древность, которая проявляется как в присутствии группы вымерших видов, характерных для ископаемых флор первой половины плейстоцена, так и в наличии у ряда сохранившихся до нашего времени видов архаичных морфологических признаков, унаследованных от формпредков. Особого внимания заслуживает находка ископаемого вида Carex paucifloroides, описанного из позднеплиоценовой флоры д. Дворца на Днепре (Величкевич, 1975) и обнаруженного во многих ранне- и среднеплейстоценовых флорах Восточно-Европейской равнины. Интересна находка альдрованды, которая по своим основным морфологическим признакам вполне сопоставима с лихвинским видом A. dokturovskyi Dorof. Широко распространенный в микулинских флорах современный вид A. vesiculosa L. отличается бо́льшей величиной и симметричностью семян. Отчетливые черты древности несут в себе орешки Ranunculus cf. sceleratoides, которые в целом мельче, более тонкостенны, а по скульптуре рельефнее современных $R$. sceleratus. Доля экзотического элемента карукюлаской флоры может быть пополнена за счет таких бесспорно древних, скорее всего вымерших форм, как своеобразные Nymphaea sp., Nuphar, лишь отдаленно напоминающие $N$. lutea, явно внеевропейский мелкоплодный Potamogeton, остатки которого обильны почти в каждой лихвинской флоре средней полосы Восточно-Европейской равнины.

Особо следует отметить своеобразие группы древесных и кустарниковых пород, в частности обилие остатков ели и одновременное присутствие сосны и лиственницы. В карукюлаской флоре по макроостаткам, безусловно, преобладает ель, что в сочетании с практически полным отсутствием широколиственных пород - непременных компонентов микулинских флор (Величкевич, 1973) - делает ее вполне сопоставимой с семенными флорами лихвинского межледниковья. Об этом же свидетельствует наличие ряда вымерших травянистых видов, в том числе специфичных 
для лихвинских флор, и сильная степень фоссилизации растительных остатков.

Палинологическое исследование новой серии образцов из шурфов А и Д проводилось по несколько измененной методике, что заметно сказалось на выразительности приводимой спорово-пыльцевой диаграммы разреза Карукюла в сравнении с ранее опубликованными (рисунок, табл. 2). Образцы сапропелита и торфов не обрабатывались, как прежде, перекисью водорода, а кипятились в течение 5 мин в $10 \%$-ном растворе едкого калия и затем ацетилировались в течение 1 мин. В результате такой обработки удалось получить несколько бо́льшее количество пыльцы трав, граба и дуба, что привело к относительному снижению содержания пыльцы липы. В целом же на новой диаграмме выделяются пыльцевые зоны, аналогичные описанным ранее (Лийвранд, 1972), за исключением некоторых изменений в количественном содержании пыльцы.

При сравнении развития карукюлаской флоры с уже известными межледниковыми флорами обнаруживается ее наибольшее сходство с лихвинской. Это выражается в хорошей сопоставимости пыльцевых зон разреза Карукюла и разрезов лихвинского межледниковья Прибалтики (табл. 3). Во всех этих разрезах, так же как и в других одновозрастных разрезах Восточно-Европейской равнины (Гричук, 1961), прослеживается раннее появление ели с ольхой (зоны I) и их широкое развитие в первой половине межледниковья (зоны II). Во время климатического оптимума участие ели несколько уменьшается, но она продолжает встречаться в большом количестве в составе пихтово-широколиственных лесов Прибалтики (зоны III). Обращает на себя внимание некоторое запаздывание в Карукюла максимумов граба и пихты, которые кульминируют в следующей зоне (IV) вместе с елью, причем их меньшее против обычного содержание связано, видимо, с более северным положением карукюлаского разреза. Примечательно, что и в Латвии максимумы граба и пихты тесно связаны с верхним максимумом ели. Далее прослеживается развитие

Таблица 3

\section{Корреляция по пыльцевым зонам карукюласких и лихвинских межледниковых отложений Прибалтики}

\begin{tabular}{l|c|c}
\hline Литва (Кондратене, 1965) & Латвия (Даниланс и др., & Карукюла (Лийвранд, \\
$1964)$ & 1972)
\end{tabular}

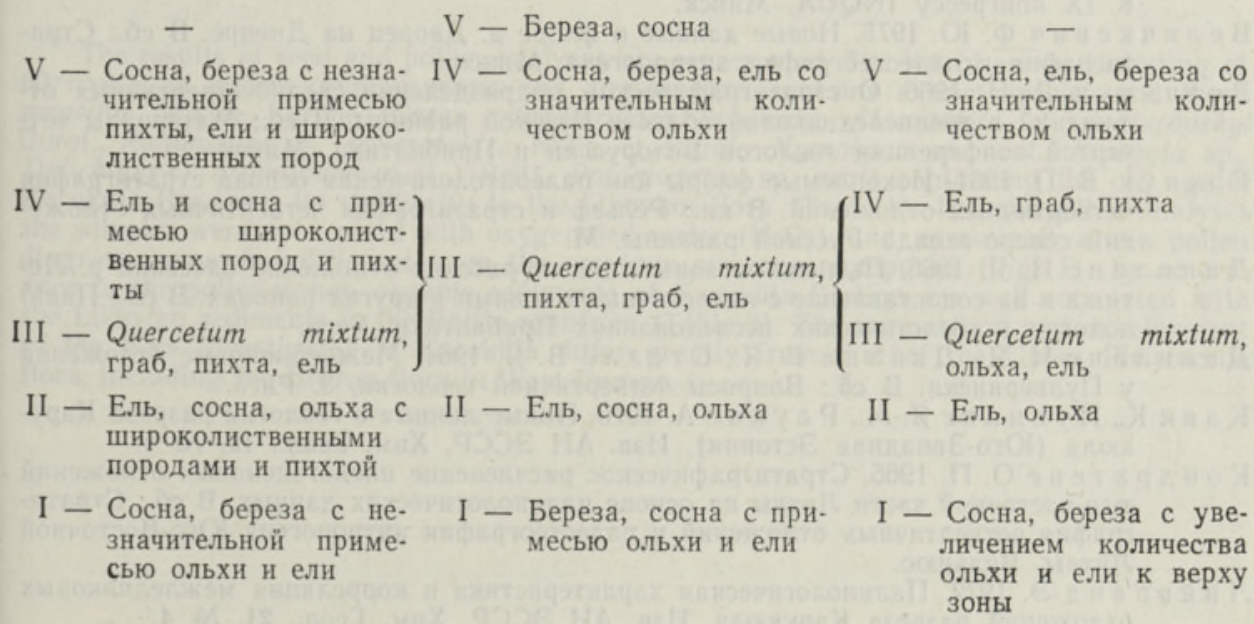


елово-сосновых лесов с березой и ольхой. Характерной чертой лихвинских флор является также высокое по сравнению с лещиной содержание ольхи, количество которой в Карукюла несколько больше обычного.

По палинологическим данным в разрезе Карукюла определены следующие межледниковые виды: Trapa natans L., Tilia platyphyllos Scop., Abies alba Mili., Osmunda cinnamomea L., O. cf. claytoniana, Tilia cf. tomentosa Moench, Picea sect. Omorica, из которых три последних также говорят в пользу среднеплейстоценового возраста разреза.

При сопоставлении спорово-пыльцевых диаграмм разреза Карукюла и брёрупского интерстадиала, в частности разреза Конин-Марантув в Польше (Borówko-Dłužakowa, 1967), обнаруживается их явное несоответствие. Начальная и конечная из трех выделяемых в КонинМарантув фаз развития растительности характеризуются господством разреженных березово-сосновых субарктических лесов, в то время как в Карукюла начальная фаза знаменуется преобладанием ели и ольхи, заметную роль играет ель и во время конечной фазы. Между тем известно, что в начале мазовецкого (лихвинского) межледниковья ель в Польше имела широкое распространение (Dyakowska, 1952), что хорошо увязывается со спорово-пыльцевыми спектрами разреза Карукюла. Отличительной чертой разреза Конин-Марантув является и небольшое содержание пыльцы пихты (до $3 \%$ ), граба (до $5 \%$ ), дуба (до $2 \%$ ), вяза (до $1 \%$ ), количество которой в случае одновозрастности данного разреза с разрезом Карукюла при его более южном положении должно бы быть гораздо большим.

Высокое содержание пыльцы липы, достигающее в одном образце из Конин-Марантув $21 \%$, вряд ли можно считать надежной основой для корреляции, так как оно могло явиться результатом локальных условий. K тому же образцы из этого разреза обрабатывались перекисью водорода, влияние которой следовало бы проверить.

Таким образом, данные палеокарпологических и спорово-пыльцевых исследований разреза Карукюла согласно свидетельствуют о межледниковом типе этой флоры, ее бесспорной древности и показывают ее хорошую сопоставимость с лихвинскими межледниковыми флорами ВосточноЕвропейской равнины.

\section{ЛИТЕРАТ У Р А}

В ели и ке в и ч Ф. Ю. 1973. Антропогеновые флоры Белоруссии и смежных областей. K IX конгрессу INQUA. Минск.

В ел и ч к в и ч Ф. Ю. 1975. Новые данные о флоре д. Дворец на Днепре, В сб.: Стратиграфня и палеогеография антропогена. Минск.

В оз н я у к Л. Н. 1966. О стратиграфическом подразделении среднечетвертичных отложений в древнеледниковой области Русской равнины. В сб.: Материалы четвертой конференции геологов Белоруссии и Прибалтики. Минск.

Г р и ч у к В. П. 1961. Ископаемые флоры как палеонтологическая основа стратиграфии четвертичных отложений. В кн.: Рельеф и стратиграфия четвертичных отложений северо-запада Русской равнины. М.

Д а н и л а н с И. Я. 1966. Пыльцевые зоны миндель-рисских отложений бассейна р. Летижа и их сопоставление с аналогичными зонами в других районах. В сб.: Палинология в геологических исследованиях Прибалтики. Рига.

Д ан ил анс И. Я., Д зилна В. Я., Стелле В. Я. 1964. Межледниковые отложения у Пулверниеки. В сб.: Вопросы четвертичной геологии, 3. Рига.

К а я к К., Пунн и н Г Я.-М., Р а у к а с А. 1970. Новые данные о геологии разреза Карукюла (Юго-Западная Эстоння). Изв. АН ЭССР, Хим. Геол., 19, № 4.

К онд р а тен е О. П. 1965. Стратиграфическое расчленение плейстоценовых отложений юго-восточной части Литвы на основе палинологических данных. В сб.: Стратиграфня четвертичных отложений и палеогеография антропогена Юго-Восточной Литвы. Вильнюс.

Л и й в р а нд Э. 1972. Палинологическая характеристнка и корреляция межледниковых отложений разреза Карукюла. Изв. АН ЭССР, Хим. Геол 21 , № 4. 
О р в ику К. К. 1956. Стратиграфическая схема антропогеновых (четвертичных) отложений территории Эстонской ССР. Тр. Ин-та геол. АН ЭССР, I.

О р в и ку К. К., Пи р р у с Р. О. 1965. Межморенные органогенные отложения в Карукюла (Эстонская ССР). В сб.: Литология и стратиграфия четвертичных отложений Эстонии. Таллин.

П унниннг Я.-М. К., Р аука с А. В., С еребрянный Л. Р. 1967. Геохронология последнего оледенения Русской равнины в свете новых радиоуглеродных датировок ископаемых озерно-болотных отложений Прибалтики. В сб.: Материалы II симпозиума по истории озер Северо-Запада СССР. Минск.

Borówko-D ł u źa kowa Z. 1967. Badania paleobotaniczne osadów mlodoplejstocenskich (Brørup) w Koninie-Marantówie. Instytut Geologiczny, Prace, t. 48, Warszawa.

D y a s ow s k a J. 1952. Interglacial w Nowinach Zukowskich kolo Lublina. Panstw. Inst. Geol. Bjul., 66, t. 2. Warszawa.

Ннститут геохимии и геофизики

Академии наук Белорусской ССР

Поступила в редакцию

$16 / X 1975$

Институт геологии

Академии наук Эстонской ССР

F. VELITSKEVITS, Elsbet LIIVRAND

\section{UUSI ANDMEID KARUKULA JÄÄVAHEAEGSE FLOORA ARENGUST}

Esitatakse Karuküla organogeensete setete paleokarpoloogilise ja palünoloogilise analüüsi tulemused. Proovid sisaldasid rikkalikult taimede seemneid (60 nimetust), neist osa on välja surnud vōi kasvab tänapäeval väljaspool Euroopat (Carex paucifloroides Wieliczk., Aldrovanda cf. dokturovskyi Dorof., Ranunculus cf. sceleratoides Nikit. et Dorof., Nymphaeae sp. exot. Brasenia sp. Dulichium cf. arundinaceum (L.) Britt., Potamogeton sp. exot). See vôimaldab Karuküla floora vanust seostada lihvini 'jäävaheaja floora omaga (tab. 1). Uus õietolmudiagramm (joonis), mille koostamisel analüüsitud setteid ei töödeldud vesinikülihapendiga, erineb õietolmı ja eoste protsentuaalse koostise poolest varem avaldatud diagrammidest ning on õietolmuvööde järgi hästi kotreleeritav Baltimaade lihvini jäävaheaja diagrammidega (tab. 3). Karuküla floora koostis ja selle areng erinevad kogu hilispleistotseeni, sealhulgas brörupi (Lääne-Euroopas) interstadiaalse floora omast.

\section{F. VELICHKEVICH, Elsbet LIIVRAND}

\section{NEW INVESTIGATIONS OF THE INTERGLACIAL FLORA FROM KARUKOLA SECTION IN ESTONIA}

The results of seed and pollen analyses are represented. The list of seeds consisting of 60 names of spores, gymnosperms and angiosperms contains extinct species and those growing outside Europe (Carex paucifloroides Wieliczk., Aldrovanda cf. dokturovskyi Dorof., Ranunculus cf. sceleratoides Nikit. et Dorof., Nymphaea sp. exot., Brasenia sp., Dulichium cf. arundinaceum (L.) Britt., Potamogeton sp. exot), confirming the old age of Karuküla flora and its similiarity to the Likhvian flora (Table 1). In new pollen analyses the samples were not treated with oxygenated water $\left(\mathrm{H}_{2} \mathrm{O}_{2}\right)$, and, as a result, a new pollen diagram, somewhat different from the previous one, was composed (Fig. 1). In accordance to the pollen zones, organic sediments of Karuküla Section are well correlated with the Likhvian sediments in the Baltic countries (Table 3 ). The composition and development of the flora investigated in Karuküla differ greatly from that of the Upper Pleistocene flora, including the Brörup flora in West Europe. 